\title{
Construction and Management of Internet of Things Training Room
}

\author{
Hong Du \\ Inner Mongolia Technical College of Mechanics and Electrics, Hohhot Inner Mongolia, 010070, \\ China
}

Keywords: Vocational and technical college, Internet of Things, Training room, Construction, Management.

\begin{abstract}
Internet of Things (IOT) specialty belongs to an emerging specialty established by vocational and technical college. The article analyzes the significance of the construction of Internet of Things training room from the construction goals and the function orientations of Internet of Things training room and puts forward the construction plan and measures of operation and management of Internet of Things training room, expecting to improve the level of the construction of specialties in vocational and technical college and help to promote the specialty teaching reform to some extent.
\end{abstract}

\section{The construction goals and the function orientations of Internet of Things training room}

\section{The construction goals of Internet of Things training room.}

The Internet of Things training room in the vocational and technical college should be constructed by following the principles of advancement, cost character, applicability and demonstration. The construction should take the fully understanding of enterprise and industry's demand for talents as the premise to construct software design and hardware platform combined with logistics supply chain management process. Besides, a comprehensive training room is required to be built up through the introduction of automation technology, modern management technology, the Internet of Things technology, system engineering technology etc. to make it meet the needs of teaching and research. The construction of Internet of Things training room should take simulation of logistics supply chain process of Internet of Things as the basis, take advanced information technology and logistics information management system as the support. Technologies include, for example, electronic tag technique, RFID technique, bar code technique and automatic control system etc. In addition, the construction should focus on standard logistics business process and use human-computer interaction operation as the method to realize, and provide a good platform for professional teaching with fully embodiment of the advantages of modern teaching methods to meet the demand of talents cultivation.

\section{The function orientations of Internet of Things training room.}

The Internet of Things training room should take training applied and technical personnel as the goal, determining the function orientation closely around the education and teaching tasks of vocational and technical colleges, specifically including:

\section{1) The function of teaching}

The room should provide trainings in aspects of professional foundation, curriculum design etc.with the function of teaching realized by three systems including interactive system, online system, and multimedia system. As for interactive system between teachers and students, teachers can demonstrate the teaching content by using the receiving equipment and let students watch it on the terminal equipment. Students can have interactive communications with teachers through the terminal equipment. The system records the data during interaction automatically. Teachers can use the interaction system to evaluate students' learning situation. As for the online system, teachers can publish their teaching material to the online teaching platform and answer the questions put forward by students on the platform. Students can communicate with teachers through the online teaching platform to get the demanded learning material and finish their homework online. As for the electronic classroom, wherein teachers can demonstrate real-time teaching content and observe students' learning situation through monitor screen, have remote control on the system. 


\section{2) The function of doing experiments}

This function is realized through the experiment hardware platform and the management platform. As for the hardware platform, it can realize the functions of data collection, wireless communication and data processing to provide experiment modules for all teaching content related to Internet of Things specialty. The realization of the hardware platform should rely on techniques such as GPS development, gateway of Internet of Things, uhf RFID, wireless sensor network, GPRS communication development, the wireless SCM development etc. As for the management platform, it is mainly in charge of processing, analysis, management of the data collected in the hardware platform. The operation of this platform will be realized by relying on software technology, network data transmission technology, database storage technology.

3) The function of training

Integrated systems which cover wide range of training content will be built up by using the training room to simulate the training content such as intelligent home, intelligent supermarkets, intelligent security, intelligent teaching etc. by introduction of advanced technology of Internet of Things.

\section{The significance of Internet of Things training room construction}

\section{Conducive to the realization of talent training goal.}

Internet of Things training room is an integrated training platform built up with teaching, scientific research and training. It takes the Internet of Things as the core, introducing advanced technologies such as computer network technology, information technology and communication technology etc. In the training room, it can not only organize the training programs such as intelligent video, wireless sensor network technology etc., but also simulate the actual effect of the application of Internet of Things technology in areas such as logistics industry, agriculture industry and transportation industry to realize students' unique design and innovative concept. So, the construction of Internet of Things training rooms can provide students with a teaching platform which combines theory with practice of learning. The training room can cultivate students' operating skills and innovation ability through providing students with technical support on aspects of perceptual experience, design innovation and the actual test and verification etc., further laying the foundation for their growing into high-tech talents of Internet of things.

\section{Conducive to promoting the educational reform of Internet of Things specialty.}

At present, all vocational colleges have set up Internet of Things related majors to meet the demand of social and economic development for talents of Internet of Things. However, in the teaching of Internet of Things specialty, the traditional teaching mode with separation between theory and practice has been difficult to meet the need of talent cultivation, and there is relatively less practice links arranged by vocational and technical colleges, which is not beneficial to the cultivation of students' ability of handling and operating. While the construction of Internet of Things training room can provide students with enough training opportunities, encouraging students to apply theoretical knowledge to practice. It can improve the current teaching situation of being lack of training courses and enrich practical teaching methods so as to promote the reform and innovation of teaching on Internet of Things related specialties in vocational and technical colleges.

Conducive to the implementation of the school-running pattern with an integration of industry, university and research.

In the process of the construction and management of Internet of Things training room, just relying on vocational and technical colleges' own strength is not enough. The cooperation between schools and enterprises needs to be strengthened to take the road of integration of industry, university and research together. Before the construction of training room, colleges should actively explore construction fund share mechanism with enterprises and guide enterprises to participate in the technology research and development work of training room construction, create Internet of Things training platform together with enterprises. At the same time, schools also should give enterprises a certain training room access to let enterprises research core technology, finish the research topic together with schools to increase the utility value of the training room. 


\section{The construction of Internet of Things training room}

\section{Internet of Things training room construction plan.}

In order to realize the function of the Internet training room, it can be built from the following three levels.

1) The perception level

This level is mainly in charge of identifying, perceiving and gathering the underlying node information of Internet of Things system. The node information includes information on aspects of status, location and use etc. This level uses qr code tag identification, RFID tag identification and other devices to support. When forming a perception level, perception equipment and induction equipment must be reasonably selected and equipped with data transmission interface to ensure the relevant data uploaded to the network system.

2) The network level

This level is the core level to realize the function of training room. Seamless connection with the internet should be realized here. Besides, transmission and application of node information should be realized through the use of network communication exchange equipment such as routers, acquisition cards and switches etc. Wireless local area network (LAN) and sensor network are the components of the network level. The former realizes a complete coverage of signal through relying on the router, equipment of the bottom level is docked with the top level data management equipment through data interface to realize wireless transmission of data information and wireless mobile management on equipment; the latter gets and handles the related information of the target objects through sensors, positioning devices, controlling the objects which need to be monitored by sensor network.

3) The application level

This level is based on the network level and perception level. It develops the system application according to the specific application environment. It edits and processes the transmission data information of the above two levels so as to convert it into data which has application values and provide decision basis for the user. The application level does not have versatility. It should fully consider the background of the Internet of Things technology environment, combined with the actual needs of users to ensure the pertinence of the development and design of this level. In the training modules of the application level, it is possible to have training on aspects of logistics management, security network communications, industrial control, environmental monitoring and public network access, etc.

\section{Construction points of the Internet of Things training room.}

\section{1) Rationalizing the construction thought}

The Internet of Things training room should be divided into different areas according to different teaching demands to make students able to carry out the learning with the combination of theory and practice according to their own needs, breaking the traditional teaching mode of separation between theory and practice to let the students learn to meet practical needs, achieve mastery through a comprehensive study of one subject, thus improving students' practice ability. At the same time, the Internet of Things training room must have wireless communication platform built in with a variety of heterogeneous networks formed to realize the transformation of different network protocols. Besides, the training room also provides a operating platform for researchers to do technology research and development and experiment through the introduction of automatic inspection technology.

\section{2) Planning the training room layout}

A reasonable layout of Internet of Things training room will be made by dividing the construction area into teaching and training area. The former is mainly used for teaching. It lets students grasp basic theoretical knowledge, clear procedures of all operation steps through teaching by equipped with relevant materials and data. The latter is mainly used for construction of all kinds of training modules by equipped with advanced facilities, providing practice places for training and scientific research. 


\section{3) Configuration of training room's hardware and software facilities}

The training room is mainly focusing on configuration of network architectures of software and hardware, which are rational equipped according to the actual demands. Due to the complexity of constitute part of the Internet of Things with sensor as its core part, when equipping sensors, the function of the router and the network terminal must be taken into consideration comprehensively to achieve fast data transmission as well as the interconnection of both the Internet of Things nodes and information effectively.

4) Solving key problems

In the construction of Internet of Things training room, the following three problems should be solved emphatically: the first is the key development of core technologies such as sensor technology, embedded intelligent technology and RFID technology etc.; The second is to establish standards of Internet of Things, paying close attention to the development direction of international Internet of Things in training room construction with reference to the international Internet of Things standards to ensure Internet of Things laboratory construction standards have reached the international advanced level; The third is to solve the safety problem of Internet of Things, that is, protecting the security of the information data transmission by the application of safety protection technology.

\section{Management on Internet of Things training room}

\section{Operation management of Internet of Things training room.}

In the building of the Internet of Things training room, in order to reduce the pressure of construction funds, vocational and technical colleges can actively guide the enterprises closely related to Internet of Things to participate in to carry out the cooperation model of industry, university and research to create an Internet of Things training platform together so as to meet the diversified demands such as teaching and scientific research, experiment and training, technology development and promotion. After the completion of Internet of Things training room, university-enterprise joint operation management pattern can be adopted. Schools will transfer the management authority to the cooperated enterprises properly to realize win-win, the specific management modes are as follows:

1) Schools carry out teaching activities

Teaching is the basic function of Internet of Things training room. Schools should play the domain function in teaching and complete the teaching tasks by using training room. Schools can also invite talents, engineers in enterprises to participate in teaching activities of training room, passing high practical knowledge and skills on students.

2) The schools and enterprises conduct training activities

In the link of training teaching, schools should cooperate with enterprises actively to gain maximum support from enterprises. Schools will discuss with the enterprises on practice projects, topics and related technologies to enhance the practicability of training, cultivating the practical operation skills of students.

3) Research and development and promotion of the Internet of things technology between colleges and enterprises

Colleges and enterprises can work together to complete the Internet of things technology research and development project. The research and development of the guiding technology can be conducted by talents of the colleges and enterprises according to the guiding technology direction provided by the enterprises. The technology will be promoted after research and development success to give full play to the practical value of Internet of Things training room.

\section{The day-to-day management of the Internet of Things training room.}

\section{1) Entrance guard management}

Internet of Things training room should realize intelligent entrance guard management, that is, installing the automatic entrance guard management system in the training room on every door, giving different teachers different door accesses to make it easy to control teachers' use of the resources of training room, intensifying the resources management of training room. In addition, the Internet of Things training room also needs reservation management, that is, teachers and students should apply booking online in advance. Setting the entrance guard system after the booking is 
permitted by the competent department, that is, open or close for teachers and students in schedule time to realize rational planning of time of the use of training room, reduce idle or disordered arrangement of training room.

2) The equipment management

All equipment in the training room can realize remote control and intelligent management, specific management modes are as follows: For mechanical and electrical equipment management, it is possible to monitor and test the working parameters of mechanical and electrical equipment. Working parameters include parameters of equipment status, position and use. The parameter information can be transmitted to the data management system of the top level through the Internet of things network. Electrical and mechanical equipment running status can realize remote-control by data management system. As for the consumable materials management. Consumable materials can have remote monitoring through the use of Internet of Things. It will establish RFID electronic tag for each consumable material and automatically calculate and monitor total consumable materials, consumption trends, make consumable material demand plan to ensure that consumable material supplied in a timely manner.

3) The management of use

The Internet of things training room realizes a butt joint with courses arrangement system. It reasonably equips training room's using time according to the curriculum arrangement situation and the situation of the teachers' applying for the use of training room. It automatically schedules the time of use to increase the service efficiency of the training room.

\section{Conclusion}

In general, vocational and technical colleges should pay attention to the Internet of things training room construction and management, lay a material foundation for promoting teaching reform of IOT specialty and realizing the goal of cultivating the talents of Internet of things. In the construction of Internet of things training room, vocational and technical colleges should actively cooperate with the enterprise to improve the training room construction standards and ensure the advancement, applicability and demonstration nature of the training room. And the vocational and technical colleges should strengthen the management of the use of training room after completion, fully play the application values of training room in teaching and research, practice of students.

\section{Acknowledgments}

Topic name of this article: Research on the construction plan of innovative Internet of things application technology specialty training room based on the concept of "without borderline", serial number: NJSY16427.

\section{References}

[1] Guo-sheng Hu, Xin-xing Wu, Xiao Jia, Fang Long Xiong. Higher vocational and technical college IOT RFID training room design and implementation, Journal of computer education, 2015 (10) : 102-104.

[2] Peng Wen Hua. Five-year higher vocational students' Internet of things specialty training base construction case study, Journal of Internet of Things technology, 2015 (2) : 85-86.

[3] Xin-xin hu. IOT specialty laboratory construction study, Journal of laboratory science, 2013 (6) : 46 to 48.

[4] Li Jianbing, Dang Li Ming, Pan Xiang Feng. IOT training system construction analysis, Journal of experimental science and technology, 2014 (4) : 122-123.

[5] Peng Ling, Huang Songfa. Study on IOT training room construction in colleges and universities, Computer knowledge and technology, 2014 (12) : 75-77. 